\title{
Desempenho de novilhas leiteiras sob manejo para crescimento compensatório recebendo suplementação com ionóforo' ${ }^{1}$
}

\author{
Patrícia Barcellos Costa ${ }^{2}$, Augusto César de Queiroz ${ }^{3}$, Marcelo Teixeira Rodrigues ${ }^{3}$, André \\ Luiz Rodrigues Magalhães ${ }^{4}$, Marcone Geraldo Costa ${ }^{5}$, Fábio Luiz Buranelo Toral ${ }^{6}$, Thony \\ Assis Carvalho ${ }^{7}$, Luana Monteiro ${ }^{8}$, Karina Zorzi ${ }^{9}$, Márcio de Souza Duarte ${ }^{8}$
}

${ }^{1}$ Parte da tese de Doutorado da primeira autora, financiada pelo CNPq.

2 Doutora em Nutrição e Produção de Ruminantes pela Universidade Federal de Viçosa.

3 Departamento de Zootecnia - UFV, Viçosa-MG. Bolsista do CNPq.

4 Universidade Federal Rural de Pernambuco - Unidade Acadêmica de Garanhuns - UFRPE/UAG.

5 Doutorando em Zootecnia, DZO - UFV, Viçosa-MG.

6 Universidade Federal de Mato Grosso.

7 Graduando em Medicina Veterinária, UFV. Bolsista PIBIC/CNPq.

8 Graduando em Zootecnia, UFV. Bolsista PIBIC/CNPq.

${ }^{9}$ Mestranda em Zootecnia, DZO - UFV, Viçosa-MG.

RESUMO - Objetivou-se avaliar a influência do manejo para crescimento compensatório e da suplementação com ionóforo sobre o desempenho de novilhas leiteiras. Foram utilizadas 20 novilhas Pardo-Suíças puras, com peso inicial de $200 \mathrm{~kg}$ e cinco meses de idade. Os tratamentos foram arranjados em um esquema fatorial ( 2 x 2) e os animais foram alocados aleatoriamente em cada uma das combinações. O fator 1 consistiu dos sistemas de alimentação (convencional e crescimento compensatório) e o fator 2, da utilização ou não de ionóforo (200 mg de monensina/animal/dia). Os animais do sistema convencional receberam alimentação ad libitum, enquanto os do sistema de crescimento compensatório foram submetidos a um manejo nutricional com dois períodos distintos: período de restrição energética ( 90 dias, P1) e período de realimentação (60 dias, P2). A eficiência de conversão de MS e EM consumida em ganho de peso diário foi menor durante o período de realimentação. Não houve diferença para as variáveis relacionadas ao balanço de nitrogênio dos animais do sistema convencional e daqueles submetidos ao manejo para crescimento compensatório. A inclusão de ionóforo na dieta das novilhas resultou em menor excreção de nitrogênio $(\mathrm{N})$ urinário e, conseqüentemente, a retenção de $\mathrm{N}$ foi maior no período de restrição e menor no período de realimentação, o que refletiu na eficiência de utilização do N consumido. Não houve efeito dos sistemas, da utilização de ionóforo ou do período sobre os parâmetros morfo-estruturais estudados e sobre o peso ao final do período experimental. Novilhas em crescimento compensatório apresentaram maior ganho de peso diário ao $135 \underline{0}$ e 150 으 dias do período experimental, em comparação às do sistema convencional.

Palavras-chave: balanço de nitrogênio, eficiência biológica, ganho de peso, monensina, realimentação, restrição

\section{Performance of dairy heifers on a compensatory growth regime supplemented with monensin}

\footnotetext{
ABSTRACT - The objective of this trial was to compare the effect of different feeding strategies with or without ionophore (monensin) supplementation on performance of dairy heifers. Twenty Brown-Swiss heifers averaging $200 \mathrm{~kg}$ of body weight and five months of age were used in a completely randomized design with a 2 x 2 factorial arrangement of treatments. Treatments were: two feeding regimes (conventional vs. compensatory growth) with (200 mg/animal/ day) or without monensin supplementation. Animals in the conventional feeding regime were fed ad libitum while those in the compensatory growth were fed as follows: P1) period of energy restriction (90 days); and P2) realimentation period (60 days). Efficiency of conversion of ingested DM and metabolizable energy on daily weight gain was lower during the realimentation period. However, nitrogen $(\mathrm{N})$ balance did not differ on heifers receiving the conventional feeding regime compared to those receiving the compensatory growth regime. Inclusion of monensin in diet of heifers reduced the excretion of $\mathrm{N}$ in urine leading to greater $\mathrm{N}$ retention in the restriction period and lower during the realimentation phase. There was not effect of treatments, monensin or period on the development measurements and final body weight. Heifers in the compensatory growth regime had greater average daily gain at 135 and 150 days when compared to conventional feeding heifers.
}

Key Words: biological efficiency, daily gain, monensin, nitrogen balance, realimentation, restriction 


\section{Introdução}

Estimativas indicam que 15 a $20 \%$ do custo total da produção de leite é decorrente de programas de criação de novilhas para reposição do rebanho e que $50 \%$ desse custo de produção resulta da alimentação dos animais.

A eficiência de utilização dos alimentos é considerada o principal fator nutricional a afetar a rentabilidade das propriedades leiteiras (Bauman et al., 1985), visto que as perdas resultantes do processo digestivo são expressivas. Estima-se que aproximadamente $30 \%$ da energia consumida é utilizada para produção de leite; $30 \%$ é excretada nas fezes; $3 \%$ na urina; $10 \%$ na forma de metano e $25 \%$ é eliminada na forma de calor (Miller \& Wolin, 2001). Portanto, minimizar as perdas que ocorrem durante a digestão e o metabolismo de nutrientes pode ser um recurso para aumentar o retorno do capital investido na atividade leiteira.

O regime de nutrição compensatória com a adição de ionóforos à dieta para vacas em lactação tem sido utilizado com esse objetivo. Nesse tipo de manejo nutricional, ocorre uma combinação de fases que alterna períodos de restrição energética e de realimentação, promovendo o ganho compensatório durante a fase de realimentação (Choi et al., 1997; Park et al., 1988). A restrição energética promove redirecionamento do fluxo de energia para suprir as exigências de mantença e de reparação dos tecidos (Walford \& Crew, 1989), enquanto a realimentação após a restrição promove o direcionamento do fluxo energético para o crescimento do tecido muscular (Ford \& Park, 2001), proporcionando aumento na eficiência de conversão alimentar. Durante o período de crescimento compensatório, os animais apresentam maior desenvolvimento corporal e aumento da eficiência de utilização de energia, como resultado da redução das exigências de mantença durante o período de restrição energética (Park et al., 1987).

Os ionóforos, por sua vez, também melhoram a eficiência de conversão alimentar, pois promovem aumento na produção de propionato e diminuição de metano e dos níveis de ácido lático (Salles et al., 2001). A monensina sódica vem sendo pesquisada de forma intensiva como recurso para melhorar quimicamente a eficiência alimentar, por meio da regulação da fermentação ruminal e de seus produtos (Rumsey, 1984). De modo geral, os ionóforos têm sido utilizados como aditivos em rações para ruminantes, melhorando de 5 a $15 \%$ os ganhos de peso em animais submetidos a dietas com baixo valor energético, melhorando, portanto, a eficiência energética em novilhos zebuínos (Luchiari Filho et al., 1990) e de vacas leiteiras (Ford \& Park, 2001).

No entanto, o efeito do manejo em regime de nutrição compensatória com adição de ionóforos sobre o desempen ho de novilhas leiteiras na fase pré-púbere tem sido pouco estudado, principalmente quanto às variáveis relacionadas ao crescimento animal, como ganho de peso, características morfológicas e balanço protéico. O balanço protéico pode ser utilizado como parâmetro para avaliação do desempenho dos animais, visto que altas proporções da proteína retida são utilizadas para o crescimento do tecido muscular, que contém baixos teores de MS, aproximadamente 30\%, tornando o animal mais eficiente quanto à conversão alimentar (Lana et al., 1992). Segundo Almeida (2001), em condições de consumo limitado, a taxa de ganho compensatório é reduzida e este ganho é composto principalmente de proteína e água, levando a aumento nas deposições de proteína, sem alteração nas deposições de gordura, em animais mestiços em ganho compensatório, quando comparados aos alimentados continuamente.

Neste estudo, adotou-se a eficiência energética como medida de eficiência biológica porque a energia é o nutriente mais limitante no sistema de produção pecuária. Além disso, a proteína pode ser convertida em energia no organismo animal, contribuindo para o cálculo da eficiência energética. Portanto, a eficiência é definida como o percentual de EM dos alimentos utilizados para o crescimento corporal.

Objetivou-se nesta pesquisa avaliar os efeitos do manejo para crescimento compensatório e da suplementação com ionóforo sobre as eficiências de conversão da MS e EM em ganho de peso e sobre o balanço de nitrogênio, o desenvolvimento corporal, o peso vivo e o ganho de peso diário de novilhas leiteiras.

\section{Material e Métodos}

O experimento foi conduzido no Setor de Gado de Corte do Departamento de Zootecnia, do Centro de Ciências Agrárias da Universidade Federal de Viçosa (UFV), em Viçosa, MG, durante o período de abril a setembro de 2004.

Foram utilizadas 20 novilhas Pardo-Suíças puras, com cinco meses de idade e peso inicial de $200 \mathrm{~kg}$. O delineamento experimental utilizado foi o inteiramente casualizado, sendo os tratamentos arranjados em esquema fatorial ( $2 \times 2)$, com quatro tratamentos, cada um com cinco repetições. $\mathrm{O}$ fator 1 consistiu dos sistemas de alimentação (convencional e crescimento compensatório) e o fator 2 , da utilização ou não de ionóforo (200 mg de monensina/animal/dia). Os animais do sistema convencional foram alimentadosad libitumcom dieta formulada segundo recomendações do NRC (2001) durante todo o período experimental. As novilhas do sistema de crescimento compensatório, no entanto, foram submetidas a um manejo nutricional com dois períodos distintos: no 
primeiro (P1, período restrição, 90 dias), o consumo de MS foi limitado a $2,5 \%$ do PV e a dieta continha $25 \%$ menos EM que a do sistema convencional, enquanto, no segundo período (P2, período realimentação, 60 dias), a oferta de MS e de EM não diferiu do grupo em sistema convencional.

A duração do período experimental foi de 180 dias, s endo os 30 primeiros destinados à adaptação dos animais . Os animais foram alojados em baias individuais com piso de cimento, cobertas parcialmente com telhas do tipo amianto, onde tiveram acesso permanente ao alimento e à água. A alimentação foi fornecida duas vezes ao dia, às 7 e $17 \mathrm{~h}$, permitindo-se sobras de, no máximo, $10 \%$ para os sistemas convencional e de crescimento compensatório (no período de realimentação). A dieta foi calculada para que todos os animais, independentemente do tratamento, recebessem a mesma quantidade de $\mathrm{PB}$ em todos os períodos.

A proporção dos ingredientes nas dietas encontra-se descrita na Tabela 1; a composição bromatológica dos alimentos, na Tabela 2; e a composição das dietas experimentais, na Tabela 3 .

Tabela 1 - Composição das dietas experimentais, com base na MS Table 1 - Ingredient composition of the experimental diets, DM basis

\begin{tabular}{|c|c|c|c|c|}
\hline \multirow[t]{3}{*}{$\begin{array}{l}\text { Alimento } \\
\text { Feed }\end{array}$} & \multicolumn{4}{|c|}{$\begin{array}{c}\text { Sistema de alimentação } \\
\text { Feeding regime }\end{array}$} \\
\hline & \multicolumn{2}{|c|}{$\begin{array}{l}\text { Convencional } \\
\text { Conventional }\end{array}$} & \multicolumn{2}{|c|}{$\begin{array}{l}\text { Crescimento compensatório } \\
\text { Compensatory growth }\end{array}$} \\
\hline & $\begin{array}{l}\text { Sem ionóforo } \\
\text { Without monensin }\end{array}$ & $\begin{array}{l}\text { Com ionóforo } \\
\text { With monensin }\end{array}$ & $\begin{array}{l}\text { Sem ionóforo } \\
\text { Without monensin }\end{array}$ & $\begin{array}{l}\text { Com ionóforo } \\
\text { With monensin }\end{array}$ \\
\hline & \multicolumn{4}{|c|}{ Primeiro período (First period) } \\
\hline Feno tifton 85 (Tifton 85 hay) & 60,00 & 60,00 & 60,00 & 60,00 \\
\hline Milho grão moído (Ground corn) & 15,31 & 15,31 & 2,10 & 2,10 \\
\hline Farelo de algodão (Cottonseed meal) & 23,29 & 23,29 & 36,20 & 36,20 \\
\hline Calcário calcítico (Limestone) & 0,60 & 0,60 & 1,00 & 1,00 \\
\hline \multirow[t]{2}{*}{ Mistura mineral $^{1}$ (Mineral mix) $^{2}$} & 0,80 & 0,80 & 0,70 & 0,70 \\
\hline & \multicolumn{4}{|c|}{ Segundo período (Second period) } \\
\hline Feno tifton 85 (Tifton 85 hay) & 60,00 & 60,00 & 50,00 & 50,00 \\
\hline Milho grão moído (Ground corn) & 15,10 & 15,10 & 20,10 & 20,10 \\
\hline Farelo de algodão (Cottonseed meal) & 23,50 & 23,50 & 28,50 & 28,50 \\
\hline Calcário calcítico (Limestone) & 0,60 & 0,60 & 0,60 & 0,60 \\
\hline Mistura mineral $^{1}$ (Mineral mix) & 0,80 & 0,80 & 0,80 & 0,80 \\
\hline
\end{tabular}

${ }^{1}$ Composição percentual (Percentage composition): Ca - 14\%; P - 9\%; S - 2,5\%; Mg - 2,5\%; Zn - 0,55\%, Cu - 0,15\%.

Tabela 2 - Composição bromatológica dos alimentos, na MS Table 2 - Chemical composition of the experimental feeds, DM basis

\begin{tabular}{|c|c|c|c|}
\hline \multirow[t]{3}{*}{ Item } & \multicolumn{3}{|c|}{$\begin{array}{c}\text { Alimento } \\
\text { Feed }\end{array}$} \\
\hline & $\begin{array}{c}\text { Feno tifton } 85 \\
\text { Tifton } 85 \text { hay }\end{array}$ & $\begin{array}{l}\text { Milho } \\
\text { grão moído }\end{array}$ & $\begin{array}{l}\text { Farelo de } \\
\text { algodão }\end{array}$ \\
\hline & & Ground corn & Cottonseed meal \\
\hline $\operatorname{MS}(D M)(\mathrm{g} / \mathrm{kg})$ & 826,00 & 879,80 & 901,00 \\
\hline $\mathrm{MO}(O M)(\mathrm{g} / \mathrm{kg})$ & 946,90 & 987,20 & 935,50 \\
\hline $\mathrm{PB}(C P)(\mathrm{g} / \mathrm{kg})$ & 123,20 & 84,00 & 379,00 \\
\hline NIDN (g.100/g N-total) & 63,54 & 9,96 & 9,19 \\
\hline \multicolumn{4}{|l|}{$N D I N(g .100 / g$ total $N)$} \\
\hline NIDA (g.100/g NT) & 20,01 & 4,23 & 4,51 \\
\hline \multicolumn{4}{|l|}{ ADIN $(\mathrm{g} .100 / \mathrm{g}$ total $N)$} \\
\hline $\mathrm{EE}(\mathrm{g} / \mathrm{kg})$ & 10,40 & 34,00 & 15,00 \\
\hline $\mathrm{CNF}(N F C)(\mathrm{g} / \mathrm{kg})$ & 90,00 & 694,60 & 291,50 \\
\hline FDN (NDF) (g/kg) & 794,30 & 174,60 & 250,00 \\
\hline FDA $(A D F)(\mathrm{g} / \mathrm{kg})$ & 421,60 & 58,90 & 150,00 \\
\hline LDA $(A D L)(\mathrm{g} / \mathrm{kg})$ & 57,90 & 2,30 & 46,40 \\
\hline $\mathrm{Ca}(\mathrm{g} / \mathrm{kg})$ & 3,20 & 0,80 & 2,40 \\
\hline $\mathrm{P}(\mathrm{g} / \mathrm{kg})$ & 2,30 & 7,10 & 7,70 \\
\hline $\mathrm{EM}_{1,5 \mathrm{x}}(\mathrm{Mcal} / \mathrm{kg})$ & 1,92 & 3,35 & 2,75 \\
\hline$M E_{1.5 x}(\mathrm{Mcal} / \mathrm{kg})$ & & & \\
\hline
\end{tabular}

Diariamente, para estimativa do consumo, foram registradas as quantidades dos alimentos fornecidos e das sobras, sendo elaboradas amostras compostas da dieta e das sobras, por animal e por período, que foram congeladas para análises posteriores. Quinzenalmente, foram feitas amostras compostas da dieta e das sobras, procedendo-se à amostragem dos alimentos a cada nova partida utilizada. Nos alimentos, foram determinadas as concentrações de MS, nitrogênio total (NT), EE, cinzas, Ca e P, segundo técnicas descritas por Silva \& Queiroz (2002). Determinaram-se ainda os teores de FDN e FDA, segundo Van Soest et al. (1991), de nitrogênio insolúvel em detergente neutro (NIDN) e nitrogênio insolúvel em detergente ácido (NIDA), conforme descrito por Licitra et al. (1996); e de lignina em ácido sulfúrico (LDA), segundo metodologia relatada por Pereira \& Rossi Jr. (1995). Nas sobras foram determinados os teores de MS, NT, EE, cinzas e FDN. 
Tabela 3 - Composição bromatológica das dietas experimentais, com base na MS Table 3 - Chemical composition of the experimental diets, DM basis

\begin{tabular}{|c|c|c|c|c|}
\hline \multirow[t]{3}{*}{$\begin{array}{l}\text { Alimento } \\
\text { Feed }\end{array}$} & \multicolumn{4}{|c|}{$\begin{array}{c}\text { Sistema de alimentação } \\
\text { Feeding regime }\end{array}$} \\
\hline & \multicolumn{2}{|c|}{$\begin{array}{l}\text { Convencional } \\
\text { Conventional }\end{array}$} & \multicolumn{2}{|c|}{$\begin{array}{c}\text { Crescimento compensatório } \\
\text { Compensatory growth }\end{array}$} \\
\hline & $\begin{array}{l}\text { Sem ionóforo } \\
\text { Without monensin }\end{array}$ & $\begin{array}{l}\text { Com ionóforo } \\
\text { With monensin }\end{array}$ & $\begin{array}{l}\text { Sem ionóforo } \\
\text { Without monensin }\end{array}$ & $\begin{array}{l}\text { Com ionóforo } \\
\text { With monensin }\end{array}$ \\
\hline & \multicolumn{4}{|c|}{ Primeiro período (First period) } \\
\hline $\operatorname{MS}(D M)(\mathrm{g} / \mathrm{kg})$ & 853,70 & 853,70 & 856,70 & 856,70 \\
\hline $\mathrm{MO}(O M)(\mathrm{g} / \mathrm{kg})$ & 937,20 & 937,20 & 927,50 & 927,50 \\
\hline $\mathrm{PB}(C P)(\mathrm{g} / \mathrm{kg})$ & 175,00 & 175,00 & 212,90 & 212,90 \\
\hline $\mathrm{EE}(E E)(\mathrm{g} / \mathrm{kg})$ & 14,90 & 14,90 & 12,40 & 12,40 \\
\hline $\mathrm{CNF}(N F C)(\mathrm{g} / \mathrm{kg})$ & 228,20 & 228,20 & 174,10 & 174,10 \\
\hline $\mathrm{FDN}(N D F)(\mathrm{g} / \mathrm{kg})$ & 572,00 & 572,00 & 581,20 & 581,20 \\
\hline $\mathrm{Ca}(\mathrm{g} / \mathrm{kg})$ & 5,40 & 5,40 & 6,20 & 6,20 \\
\hline $\mathrm{P}(\mathrm{g} / \mathrm{kg})$ & 3,90 & 3,90 & 5,00 & 5,00 \\
\hline \multirow[t]{2}{*}{$\mathrm{EM}_{1,5 \mathrm{x}}(\mathrm{Mcal} / \mathrm{kg})\left(M E_{1.5 x}\right)$} & 2,34 & 2,34 & 2,28 & 2,28 \\
\hline & \multicolumn{4}{|c|}{ Segundo período (Second period) } \\
\hline $\operatorname{MS}(D M)(\mathrm{g} / \mathrm{kg})$ & 853,80 & 853,80 & 860,20 & 860,20 \\
\hline $\mathrm{MO}(O M)(\mathrm{g} / \mathrm{kg})$ & 937,00 & 937,00 & 938,50 & 938,50 \\
\hline $\mathrm{PB}(C P)(\mathrm{g} / \mathrm{kg})$ & 175,70 & 175,70 & 186,50 & 186,50 \\
\hline $\mathrm{EE}(\mathrm{g} / \mathrm{kg})$ & 14,90 & 14,90 & 16,30 & 16,30 \\
\hline $\mathrm{CNF}(N F C)(\mathrm{g} / \mathrm{kg})$ & 227,40 & 227,40 & 267,70 & 267,70 \\
\hline $\mathrm{FDN}(N D F)(\mathrm{g} / \mathrm{kg})$ & 572,20 & 572,20 & 512,20 & 512,20 \\
\hline $\mathrm{Ca}(\mathrm{g} / \mathrm{kg})$ & 5,40 & 5,40 & 5,90 & 5,90 \\
\hline $\mathrm{P}(\mathrm{g} / \mathrm{kg})$ & 3,90 & 3,90 & 3,80 & 3,80 \\
\hline $\mathrm{EM}_{1,5 \mathrm{x}}(\mathrm{Mcal} / \mathrm{kg})\left(M E_{1.5 x}\right)$ & 2,31 & 2,31 & 2,42 & 2,42 \\
\hline
\end{tabular}

Os teores de CNF foram obtidos por meio da equação: $\mathrm{CNF}=100-(\% \mathrm{~PB}+\% \mathrm{EE}+\%$ cinzas $+\% \mathrm{FDN})$, segundo $\mathrm{Van}$ Soest et al. (1991).

A concentração de energia dos alimentos foi estimada segundo Van Soest (1994), utilizando-se a equação: $\mathrm{NDT}=\mathrm{DMS}-\operatorname{cinzas}+1,25 \times(\mathrm{EE})+1,9$, em que DMS é a digestibilidade da matéria seca, obtida como: DMS = $(100-\mathrm{FDN}) * 0,98+($ FDN*DFDN/100) $-12,8$. DFDN é a digestibilidade estimada da FDN, calculada como: $D F D N=$ 147,3 - 78,9 $\log _{10}$ [(LDA/FDA)*100], em que LDA representa o conteúdo de lignina do alimento. A conversão dos valores de NDT para EM foi realizada por meio da equação: $\mathrm{EM}(\mathrm{Mcal} / \mathrm{kg})=1,01 \mathrm{x} \mathrm{ED}(\mathrm{Mcal} / \mathrm{kg})-0,45$, em que ED é o teor de energia digestível, obtido como: $\mathrm{ED}(\mathrm{Mcal} / \mathrm{kg})=$ 0,04409 x NDT (\%). Ambas as equações foram propostas pelo NRC (2001).

Os três dias que antecederam o término dos períodos foram utilizados para determinação da digestibilidade das dietas. No $1 \underline{0}$, 2으 e $3 \underline{0}$ dias, respectivamente, às 8,12 e 16h, foram coletadas amostras de fezes, diretamente do reto dos animais. As amostras foram pré-secas em estufa de ventilação forçada, a $60^{\circ} \mathrm{C}$ por 72 horas, eprocessadas em moinho de faca com peneira de crivos de $1 \mathrm{~mm}$, elaborando-se uma amostra composta por animal, com base no peso seco de cada subamostra.
Para determinação da produção de MS fecal, foi utilizada a FDAi como indicador interno, conforme técnica descrita por Cochran et al. (1986). Entretanto, efetuou-se a incubação ruminal em sacos de ankon (filter bags F57), por 144 horas, em vez de utilizar a digestibilidade invitro, sugerida no protocolo original. Foram incubadas amostras das sobras, das fezes e dos ingredientes utilizados nas dietas. O material remanescente da incubação foi submetido à fervura em detergente ácido por 1 hora e o resíduo foi considerado FDAi.

Ovalor de energia das dietas foi estimado utilizando-se os dados de digestibilidade obtidos: $\mathrm{NDT}(\%)=\mathrm{dCNF}+\mathrm{dPB}$ $+(\mathrm{dEE} \times 2,25)+\mathrm{dFDN}$, em que $\mathrm{d}$ representa a digestibilidade dos respectivos componentes.

Para determinação do balanço de nitrogênio no 850 e 145으 dias do período experimental, alíquotas de $50 \mathrm{~mL}$ de urina foram obtidas de todos os animais aproximadamente 4 horas após a alimentação, durante micção estimulada por massagem na vulva. A urina foi filtrada e alíquotas de $10 \mathrm{~mL}$ foram retiradas e imediatamente armazenadas a $-15^{\circ} \mathrm{C}$, para posteriores análises dos níveis de compostos nitrogenados totais e de creatinina. Os teores de creatinina foram determinados pelo sistema colorimétrico com reação de ponto final (kit comercial). Adotou-se a seguinte equação para determinação da excreção diária de creatinina (EDC): EDC 
$(\mathrm{mg} / \mathrm{kgPV})=32,27-0,01093 * \mathrm{PV}$ (Chizzotti et al., 2004). A partir da excreção média diária de creatinina obtida no experimento (mg/kg PV/dia) e da concentração de creatinina $(\mathrm{mg} / \mathrm{L})$ na amostra spot de urina, foi estimado o volume diário de urina (Silva et al., 2001). Esse volume foi utilizado para calcular as excreções estimadas diárias de nitrogênio urinário. Os compostos nitrogenados fecais foram estimados em $5 \mathrm{~g} / \mathrm{kg}$ de MS ingerida, valor próximo ao reportado por Ladeira et al. (1999) e Valadares et al. (1997).

Para obtenção dos dados de desempenho, as novilhas foram pesadas e medidas quinzenalmente durante todo o período experimental. A pesagem foi realizada durante dois dias consecutivos, utilizando-se a média para cálculo da variação do PV e do ganho de peso diário (GPD). As características altura, largura e comprimento de garupa e altura de cernelha foram aferidas com auxílio de hipômetro e o comprimento corporal e o perímetro torácico, com fita milimétrica.

As variáveis relacionadas ao balanço de nitrogênio foram submetidas às análises de variância considerando-se modelos contendo os efeitos de sistema (SIS), de ionóforo (ION) e de período (PER), as interações entre essas fontes de variação (efeitos fixos) e o resíduo (efeito aleatório), utilizando-se o PROC GLM do Statistical Analysis System (SAS, 2000).

Quando necessário e na presença de efeitos significativos das interações, os efeitos de SIS e ION foram analisados dentro de cada PER. As diferenças entre as fontes de variação foram estimadas por meio de contrastes, aplicando-se o teste t de Student-Newman-Keulls para verificar se as diferenças eram significativas.

As variáveis relacionadas aos consumos de MS e de nutrientes, às eficiências de utilização da MS (EFCMS) e da EM (EFCEM) e às medidas morfoestruturais foram analisadas por meio de modelos lineares mistos, que consideraram os efeitos fixos de sistema (SIS), ionóforo (ION), SIS $\times$ ION, dia, SIS $\times$ dia e ION $\times$ dia e os efeitos aleatórios de repetição dentro de cada combinação $\mathrm{SIS} \times \mathrm{ION}$ e do resíduo, por meio do PROC MIXED do Statistical Analysis System (SAS, 2000).

Uma vez que as medidas repetidas estavam correlacionadas por meio da contribuição de cada animal $(\operatorname{rep}($ SIS $\times \mathrm{ION}))$, foram consideradas estruturas de co-variâncias residuais do tipo: CSH (simetria composta heterogênea) para as medidas de peso; ARH(1) (auto regressiva heterogênea de primeira ordem) para EFCMS, EFCEM, ganho de peso diário (GPD), largura (LG) e comprimento de garupa (CG), altura de cernelha (AC), comprimento corporal (CC) e perímetro torácico (PT); e AR(1) (auto-regressiva de primeira ordem) para os consumos de
MS, FDN e EM e a altura de garupa (AG). Lorenzo-Bermejo et al. (2003) e Freitas et al. (2005) apresentaram descrição detalhada dessas estruturas de co-variâncias. Os parâmetros dessas matrizes foram estimados pelo método da Máxima Verossimilhança Restrita, adotando-se o critério de convergência "default" do procedimento MIXED para a convergência.

Para as análises estatísticas das variáveis $\mathrm{LG}, \mathrm{AG}, \mathrm{CG}$, AC, CC, PT e PV, foram utilizados os resultados das medidas realizadas no $105^{\circ}, 120^{\circ}, 135^{\circ}$ e $150^{\circ}$ dias do período experimental.

Quando necessário, foram feitas comparações entre as médias estimadas para cada SIS ou dia. Nesses casos, o teste Tukey foi adotado para verificar se as diferenças eram significativas.

\section{Resultados e Discussão}

Os dados referentes aos consumos médios diários de MS, FDN e EM, estudados dentro de cada período, são apresentados na Tabela 4 (SIS $\times$ PER) e as eficiências de utilização de MS e da EM consumida são apresentadas na Tabela 5 .

Os animais submetidos ao sistema crescimento compensatório apresentaram menores consumos de MS, FDN (kg/dia, \%PV) e EM (Mcal/dia) durante o primeiro período

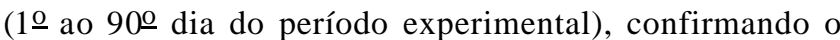
previamente estabelecido. Durante o segundo período (91으 ao 1500 dia do período experimental), o consumo não diferiu entre os sistemas, entretanto, o consumo de FDN (\%PV) pelas novilhas em crescimento compensatório foi menor, provavelmente em decorrência da relação volumoso: concentrado, que diminuiu de 60:40 para 50:50.

A eficiência de conversão de MS e EM consumida em ganho de peso foi menor durante o segundo período (do 91으 ao 150ํ dia do período experimental) (Tabela 5), o que pode ter sido conseqüência do alto consumo de MS (2,81 e $3,11 \%$ PV).

Animais com elevado consumo de MS apresentam redução na digestibilidade da dieta e na eficiência de conversão da MS em ganho de peso (Tyrrell \& Moe, 1975), visto que o coeficiente de digestibilidade dos alimentos depende de uma complexa relação entre as taxas de passagem e de digestão e dos efeitos associativos entre elas (Van Soest, 1994). Desse modo, a eficiência digestiva de determinado alimento decresce com o aumento do consumo (Van Soest, 1994). Os cálculos de NDT dos alimentos neste trabalho foram realizados segundo Van Soest (1994), considerando um declínio de $4 \%$ na digestibilidade para cadamúltiplo de consumo acima do nível de mantença. Entretanto, sabe-se 
Tabela 4 - Consumos médios diários de MS, FDN e EM conforme os sistemas de alimentação Table 4 - Average daily intakes DM, NDF and ME according to the feeding regime

\begin{tabular}{|c|c|c|c|c|c|c|c|c|}
\hline \multirow[t]{3}{*}{$\begin{array}{l}\text { Consumo } \\
\text { Intake }\end{array}$} & \multicolumn{4}{|c|}{$\begin{array}{l}\text { Sistema de alimentação } \\
\text { Feeding regime }\end{array}$} & \multirow{2}{*}{\multicolumn{2}{|c|}{$\begin{array}{c}\text { Diferença Co-CC } \\
\text { Difference Co-CG }\end{array}$}} & \multicolumn{2}{|c|}{$\begin{array}{c}\text { Nível de significância } \\
\text { Significance level }\end{array}$} \\
\hline & \multicolumn{2}{|c|}{$\begin{array}{c}\text { Convencional (Co) } \\
\text { Conventional }(\mathrm{Co})\end{array}$} & \multicolumn{2}{|c|}{$\begin{array}{l}\text { C. comp. (CC) } \\
\text { C. growth }(C G)\end{array}$} & & & & \\
\hline & $\mathrm{P} 1$ & $\mathrm{P} 2$ & $\mathrm{P} 1$ & $\mathrm{P} 2$ & $\mathrm{P} 1$ & $\mathrm{P} 2$ & $\mathrm{P} 1$ & P2 \\
\hline MS (kg/dia) $(D M, k g /$ day $)$ & 6,49 & 8,75 & 4,92 & 9,09 & $1,57 \pm 0,38$ & $-0,34 \pm 0,57$ & 0,0008 & 0,5600 \\
\hline $\mathrm{MS}(\% \mathrm{PV})(D M, \% B W)$ & 2,64 & 2,81 & 2,16 & 3,11 & $0,48 \pm 0,01$ & $-0,30 \pm 0,01$ & 0,0011 & 0,0534 \\
\hline FDN $(\% \mathrm{PV})(N D F, \% B W)$ & 1,77 & 1,79 & 1,46 & 0,99 & $0,31 \pm 0,26$ & $-0,20 \pm 0,48$ & 0,0014 & 0,0397 \\
\hline EM (Mcal/dia) (ME, Mcal/day) & 19,79 & 27,83 & 14,46 & 29,30 & $5,33 \pm 0,96$ & $-1,47 \pm 1,86$ & 0,0001 & 0,4413 \\
\hline
\end{tabular}

${ }_{1}^{1}$ Nível de significância pelo teste de Student-Newman-Keulls.

1 Significance level by Student-Newman-Keulls test.

Tabela 5 - Eficiências de conversão da MS (EFCMS) e da EM consumida (EFCEM) em ganho de peso conforme os tratamentos e os períodos

Table 5 - Conversion efficiencies of DM (EFFDMI) and ME intake (EFFEMI) according to the treatments and periods

\begin{tabular}{|c|c|c|c|c|}
\hline \multirow[t]{2}{*}{ Item } & \multicolumn{3}{|c|}{$\begin{array}{c}\text { Sistema de alimentação } \\
\text { Feeding regime }\end{array}$} & \multirow[t]{2}{*}{$\begin{array}{c}\text { Nível de significância }{ }^{3} \\
\text { Significance level }\end{array}$} \\
\hline & $\begin{array}{c}\text { Conv. }(\mathrm{Co}) \\
\text { Conv. }(\mathrm{Co})\end{array}$ & $\begin{array}{l}\text { C. Comp. }(\mathrm{CC}) \\
\text { C. Growth }(C G)\end{array}$ & $\begin{array}{l}\mathrm{Co}-\mathrm{CC} \\
\mathrm{Co}-\mathrm{CG}\end{array}$ & \\
\hline \multirow[t]{3}{*}{$\operatorname{EFCEM}(E F F E M I)(\mathrm{g} / \mathrm{Mcal})^{2}$} & $\begin{array}{l}12,96 \\
41,72\end{array}$ & $\begin{array}{l}13,12 \\
42,64\end{array}$ & $\begin{array}{l}-0,16 \pm 1,08 \\
-0,92 \pm 3,50\end{array}$ & $\begin{array}{l}0,8860 \\
0,7942\end{array}$ \\
\hline & \multicolumn{3}{|c|}{ Ionóforo (Monensin) } & \\
\hline & $\begin{array}{c}\text { Sem ionóforo (SI) } \\
\text { Without monensin }(O M)\end{array}$ & $\begin{array}{c}\text { Com ionóforo (CI) } \\
\text { With monensin }(M) M-M\end{array}$ & $\mathrm{SI}-\mathrm{CI}$ & \\
\hline \multirow[t]{3}{*}{$\operatorname{EFCEM}(E F F E M I)(\mathrm{g} / \mathrm{Mcal})^{2}$} & $\begin{array}{l}13,05 \\
42,63\end{array}$ & $\begin{array}{l}13,03 \\
41,73\end{array}$ & $\begin{array}{c}-0,03 \pm 1,08 \\
0,90 \pm 3,50\end{array}$ & $\begin{array}{l}0,9790 \\
0,7988\end{array}$ \\
\hline & \multicolumn{3}{|c|}{ Período (Period) } & \\
\hline & $\begin{array}{l}\text { Período } 1(\mathrm{P} 1) \\
\text { Period } 1(\mathrm{P} 1)\end{array}$ & $\begin{array}{l}\text { Período } 2(\mathrm{P} 2) \\
\text { Period } 2(P 1)\end{array}$ & $\mathrm{P} 1-\mathrm{P} 2$ & \\
\hline EFCMS $(E F F D M I)(\%)^{1}$ & 14,15 & 11,93 & $2,22 \pm 1,08$ & 0,0475 \\
\hline $\operatorname{EFCEM}_{(E F F E M I)}(\mathrm{g} / \mathrm{Mcal})^{2}$ & 46,97 & 37,38 & $9,59 \pm 3,50$ & 0,0100 \\
\hline
\end{tabular}

1 GPD * 100/CMS (kg/dia).

2 GPD * 1000/CEM (Mcal/dia).

${ }^{3}$ Nível de significância pelo teste de Student-Newman-Keulls.

${ }^{1}$ DWG *100/DMI (kg/day).

${ }^{2}$ DWG * 1000/EMI (kg/day).

${ }^{3}$ Significance level by Student-Newman-Keulls test.

que esse declínio não é linear. Segundo Vandehaar (1998), alimentos com alto coeficiente dedigestibilidade promovem redução ainda maior na digestibilidade conforme aumenta o consumo, podendo ocorrer declínio de $8 \%$ para cada múltiplo acima da mantença.

A diluição das exigências de mantença é outro importante fator que altera a eficiência de utilização da EM e de sua conversão em peso. Em animais em crescimento, parte dos nutrientes consumidos é direcionada para atender às exigências de mantença e o restante, para desenvolvimento corporal, caracterizado por hiperplasia e hipertrofia celular. Desta forma, quando o consumo de MS aumenta, ocorre diluição das exigências de mantença. No passado, assumia-se que, para animais em crescimento, cada Mcal adicional de EM consumida seria utilizado para aumento da massa tecidual. Entretanto, a relação entre consumo de EM e ganho de peso não é linear, pois a eficiência de conversão de EM para EL não é constante.

Por outro lado, em experimento realizado por Ford \& Park (2001), novilhas criadas em regime de crescimento compensatório ganharam mais peso e consumiram menos alimento, apresentando aumento de 1,5 vezes na eficiência de crescimento em comparação às do grupo controle. A grande variação de resultados entre experimentos pode ocorrer como conseqüência das diferentes condições experimentais, pois, além dos citados, outros fatores, como 
Tabela 6 - Balanço aparente de nitrogênio nos sistemas convencional e crescimento compensatório Table 6 - Apparent nitrogen balance in heifers on different feeding regimes

\begin{tabular}{|c|c|c|c|c|c|c|c|c|}
\hline \multirow[t]{3}{*}{ Item } & \multicolumn{4}{|c|}{$\begin{array}{c}\text { Sistema de alimentação } \\
\text { Feeding regime }\end{array}$} & \multirow{2}{*}{\multicolumn{2}{|c|}{$\begin{array}{c}\text { Diferença Co-CC } \\
\text { Difference } C o-C G\end{array}$}} & \multirow{2}{*}{\multicolumn{2}{|c|}{$\begin{array}{c}\text { Nível de significância } \\
\text { Significance level }\end{array}$}} \\
\hline & \multicolumn{2}{|c|}{$\begin{array}{c}\text { Convencional }(\mathrm{Co}) \\
\text { Conventional }(\mathrm{Co})\end{array}$} & \multicolumn{2}{|c|}{$\begin{array}{l}\text { C. comp. }(\mathrm{CC}) \\
\text { C. growth }(C G)\end{array}$} & & & & \\
\hline & $\mathrm{P} 1$ & $\mathrm{P} 2$ & $\mathrm{P} 1$ & $\mathrm{P} 2$ & P1 & $\mathrm{P} 2$ & P1 & $\mathrm{P} 2$ \\
\hline $\begin{array}{l}\mathrm{N} \text { urinário }(\mathrm{g} / \mathrm{dia}) \\
\text { Urinary } N(\mathrm{~g} / \text { day })\end{array}$ & 117,54 & 169,49 & 131,19 & 172,94 & $-13,64 \pm 12,66$ & $-3,45 \pm 25,84$ & 0,2972 & 0,8955 \\
\hline Balanço de $N(\mathrm{~g} / \mathrm{dia})^{1}$ & 85,91 & 95,60 & 68,54 & 105,98 & $17,37 \pm 8,99$ & $-10,38 \pm 14,78$ & 0,0711 & 0,4924 \\
\hline $\begin{array}{l}N \text { balance (g/day) } \\
\text { Eficiência }^{2} \\
\text { Efficiency }\end{array}$ & 47,14 & 41,11 & 41,01 & 40,27 & $6,13 \pm 4,88$ & $0,84 \pm 5,95$ & 0,2270 & 0,8891 \\
\hline
\end{tabular}

${ }^{1} \mathrm{~N}$ consumido - [( $\mathrm{N}$ fezes- $\mathrm{N}$ fecal endógeno $)+(\mathrm{N}$ urina- $\mathrm{N}$ urinário endógeno $\left.)\right]$.

2 Balanço de $N * 100 / \mathrm{N}$ consumido.

${ }^{3}$ Nível de significância pelo teste Student-Newman-Keulls.

${ }_{1}^{1} \mathrm{~N}$ intake-[(fecal $\mathrm{N}$-endogenous fecal $\left.\mathrm{N}\right)+($ urinary $\mathrm{N}$-endogenous urinary $\left.\mathrm{N})\right]$ ).

${ }^{2} \mathrm{~N}$ balance ${ }^{*} 100 / \mathrm{N}$ intake.

${ }^{3}$ Significance level by Student-Newman-Keulls test.

tamanho corporal, mudanças na massa corporal e tipo de dieta, afetam a eficiência biológica.

O efeito do crescimento compensatório sobre o metabolismo de nitrogênio $(\mathrm{N})$ tem sido observado em pesquisas com vacas leiteiras (Choi et al., 1997; Ford \& Park 2001). Entretanto, neste experimento, não houve diferença para variáveis relacionadas ao balanço de $\mathrm{N}$ entre os animais do sistema convencional e aqueles submetidos ao manejo para crescimento compensatório (Tabela 6). Quando a fermentação ultrapassa a capacidade de assimilação do nitrogênio pelos microrganismos ruminais, ocorre acúmulo de amônia e pequena retenção de nitrogênio pelo animal (AFRC, 1993). A concentração de amônia também é dependente do $\mathrm{pH}$ ruminal, pois, quanto mais baixo o $\mathrm{pH}$, menor o nível de amônia (Erfle et al., 1982). Há, portanto, maior eficiência no controle da produção de amônia em dietas com alta relação volumoso:concentrado, que proporcionam valores de $\mathrm{pH}$ mais altos (Lana et al., 1998).

A suplementação com ionóforo não teve efeito sobre a excreção de $\mathrm{N}$, o balanço de $\mathrm{N}$ e a eficiência de retenção do N consumido (Tabela 7). Segundo Russell \& Strobel (1989), a monensina reduz a produção ruminal de amônia pela inibição da população de bactérias gram-positivas, fermentadoras obrigatórias de aminoácidos e com alta capacidade de produção de amônia, como, por exemplo, as espécies Peptostreptococcus anaerobius C, Clostridium sticklandii SR e Clostridium aminophilum F. A hidrólise de proteínas por enzimas microbianas ruminais libera peptídeos, que são quebrados em aminoácidos e amônia e incorporados como proteína microbiana. Havendo menor produção de amônia, ocorre maior acúmulo de peptídeos e aminoácidos no rúmen, favorecendo seu maior fluxo para o intestino delgado, com menores perdas ruminais de proteínas dietéticas (Russell et al., 1988; Chen \& Russell, 1991). Entretanto, existem poucas informações sobre o efeito dos ionóforos no metabolismo ruminal de proteínas em animais em clima tropical. Oliveira et al. (2006) verificaram que, em condições tropicais, o tratamento com monensina não interferiu no crescimento microbiano quando comparado ao controle. A monensina inibiu a atividade específica de produção de amônia, mas não manteve a atividade específica de produção de amônia em baixos níveis, indicando reação diferente dos microrganismos ruminais de animais em clima tropical aos ionóforos, motivo provável da ausência de efeito da monensina sódica neste experimento.

As medidas morfoestruturais de altura, largura e comprimento de garupa, altura de cernelha, comprimento corporal e perímetro torácico e os valores para PV e GPD são apresentados nas Figuras 1 e 2. Não houve efeito dos sistemas de alimentação, da utilização de ionóforo ou do período sobre os parâmetros morfoestruturais estudados e sobre o peso ao final do período experimental. Contudo, sabe-se que a taxa de crescimento na fase pré-púbere é influenciada pela nutrição, pelo status hormonal e pelo ambiente ao qual o animal é submetido. Esses fatores podem inibir a divisão celular e o desenvolvimento do esqueleto ósseo, prejudicando o desenvolvimento tecidual e podendo reduzir o peso à maturidade, determinado geneticamente.

Widdowson \& Lister (1991) verificaram que severa restrição alimentar, principalmente protéica, diminuiu o peso à maturidade de bovinos, como resultadode reduções permanentes no número e na atividade de células do trato intestinal e da fibra muscular, o que não ocorreu com restrição energética moderada. 
Tabela 7 - Balanço aparente de nitrogênio com a suplementação de ionóforo Table 7 - Apparent nitrogen balance in heifers with or without monensin supplementation

\begin{tabular}{|c|c|c|c|c|c|c|c|c|}
\hline \multirow[t]{3}{*}{ Item } & \multicolumn{4}{|c|}{$\begin{array}{c}\text { Sistema de alimentação } \\
\text { Feeding regime }\end{array}$} & \multirow{2}{*}{\multicolumn{2}{|c|}{$\begin{array}{c}\text { Diferença SI-CI } \\
\text { Difference } O M-M\end{array}$}} & \multirow{2}{*}{\multicolumn{2}{|c|}{$\begin{array}{c}\text { Nível de significância }{ }^{3} \\
\text { Significance level }\end{array}$}} \\
\hline & \multicolumn{2}{|c|}{$\begin{array}{c}\text { Sem ionóforo (SI) } \\
\text { Without monensin }(O M)\end{array}$} & \multicolumn{2}{|c|}{$\begin{array}{l}\text { Com ionóforo }(\mathrm{CI}) \\
\text { With monensin }(M)\end{array}$} & & & & \\
\hline & P1 & $\mathrm{P} 2$ & P1 & $\mathrm{P} 2$ & P1 & $\mathrm{P} 2$ & P1 & $\mathrm{P} 2$ \\
\hline $\begin{array}{l}\mathrm{N} \text { urinário }(\mathrm{g} / \text { dia }) \\
\text { Urinary } N(\text { g/day })\end{array}$ & 13,02 & 15,54 & 10,77 & 18,70 & $2,25 \pm 1,67$ & $-3,15 \pm 2,58$ & 0,1965 & 0,2394 \\
\hline Balanço de $N(\mathrm{~g} / \mathrm{dia})^{1}$ & 79,60 & 91,10 & 78,53 & 97,83 & $1,08 \pm 5,51$ & $-6,74 \pm 6,19$ & 0,8477 & 0,2927 \\
\hline $\begin{array}{l}N \text { balance (g/day) } \\
\text { Eficiência }^{2} \\
\text { Efficiency }\end{array}$ & 58,83 & 52,71 & 59,30 & 55,28 & $-0,47 \pm 2,05$ & $-2,57 \pm 2,14$ & 0,8227 & 0,2475 \\
\hline
\end{tabular}

${ }^{1} \mathrm{~N}$ consumido - [( $\mathrm{N}$ fezes- $\mathrm{N}$ fecal endógeno $)+(\mathrm{N}$ urina- $\mathrm{N}$ urinário endógeno $\left.)\right]$.

2 Balanço de $N * 100 / N$ consumido.

${ }^{3}$ Nível de significância pelo teste Student-Newman-Keulls.

${ }^{1} \mathrm{~N}$ intake -[(fecal $\mathrm{N}$-endogenous fecal $\left.\mathrm{N}\right)+($ urinary $\mathrm{N}$-endogenous urinary $\left.\mathrm{N})\right]$ ).

${ }^{2} \mathrm{~N}$ balance ${ }^{*} 100 / \mathrm{N}$ intake.

${ }^{3}$ Significance level by Student-Newman-Keulls test.
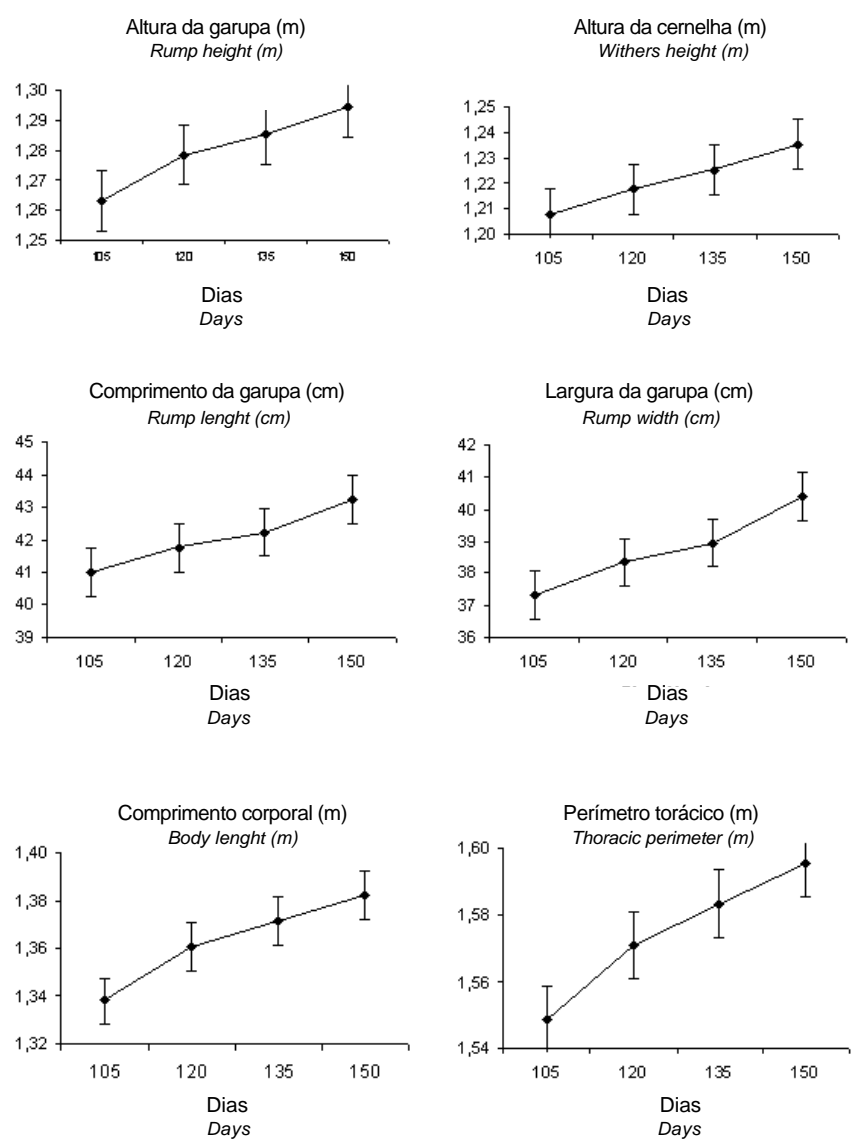

Figura 1 - Medidas de desenvolvimento corporal no período de realimentação.

Figure 1 - Measurements of body development during the realimentation period.

Oberbauer et al. (1989) demonstraram que o consumo de nutrientes pode alterar a idade de fechamento das epífises ósseas, alterando o tamanho corporal dos animais. Divers os autores (Bortone et al., 1994; Pirlo et al., 1997; Van Amburgh et al., 1998) verificaram maiores alturas de cernelha e de garupa maior comprimento corporal de novilhas leiteiras quando permitido livre acesso à ração.

No início do segundo período, as novilhas do sistema crescimento compensatório apresentaram PV inferior ao obtido no sistema convencional (Figura 1). Durante o segundo período, os animais do sistema crescimento compensatório apresentaram maior ganho de peso diário (Figura 2), o que compensou parcialmente o menor PV ao início do período. Similarmente ao observado neste experimento, Ford \& Park (2001) verificaram que novilhas submetidas ao regime de nutrição compensatória apresentaram peso corporal menor durante a fase de restrição de energia (primeiro período) se comparadas às alimentadas tradicionalmente. No período de restrição, ocorre redirecionamento do fluxo de energia para conservação das atividades essenciais, principalmente as de mantença, e das funções de reparação (Walford \& Crew, 1989). Na fase de realimentação (crescimento compensatório), com maior oferta de energia, as exigências de mantença são supridas e o excedente é direcionado para crescimento, ocorrendo aumento no ganho de peso diário e retorno ao peso normal.

Goodrich et al. (1984), em trabalho de revisão, sumarizaram dados de 24 experimentos de animais em pastejo e observaram aumento, em média, de 13,5\% (82g PV/dia) na taxa de crescimento de novilhas leiteiras sob suplementação com monensina sódica. A ausência de efeito da suplementação sobre o metabolismo do $\mathrm{N}$ pode ter sido a causa da ausência de efeitos sobre as medidas de desenvolvimento corporal, peso vivo e ganho de peso diário. 

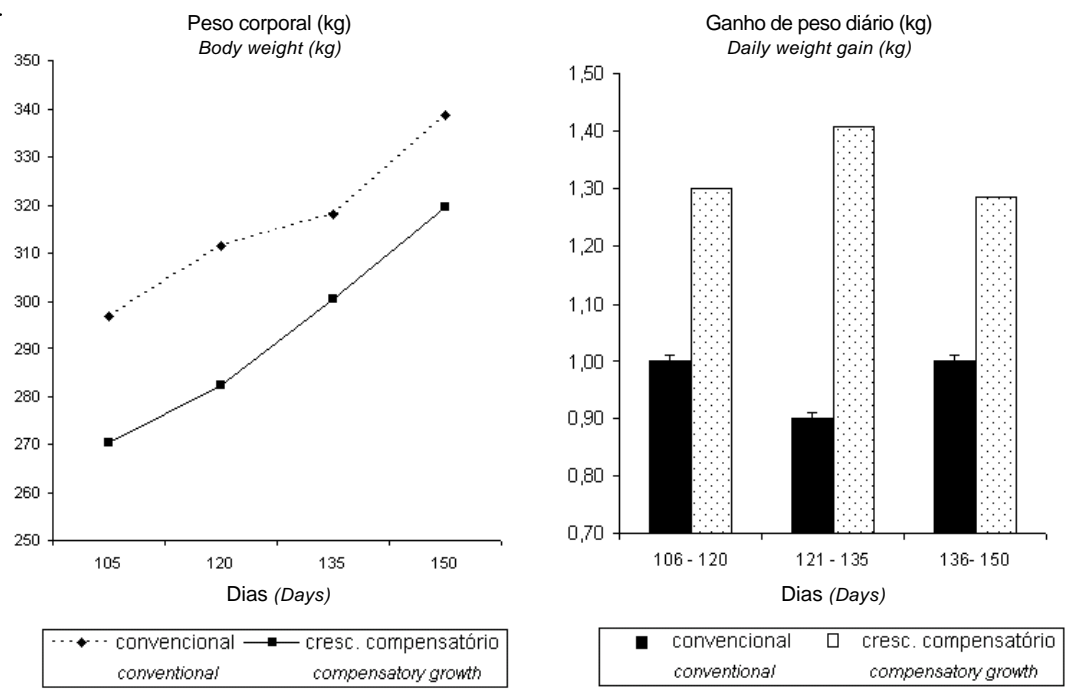

Figura 2 - Evolução do peso corporal e do ganho de peso diário durante o período de realimentação.

Figure 2 - Change of body weight and daily weigh gain during the realimentation period.

\section{Conclusões}

O manejo para crescimento compensatório com restrição energética de 25\% da EM recomendada pelo NRC (2001) durante o primeiro período e elevado consumo de MS durante o segundo período não promove aumento na eficiência de conversão da MS e da EM consumida em ganho de peso diário e, conseqüentemente, não ocasiona incremento no balanço de nitrogênio dos animais.

A restrição energética moderada (aproximadamente $25 \%$ da EM) recomendada pelo NRC (2001) não prejudica o desenvolvimento corporal, o que, neste estudo, foi evidenciado pela evolução das medidas de desenvolvimento corporal.

O período de restrição energética seguido de período de realimentação promove maior ganho de peso diário, proporcionando aos animais peso final com idade cronológica equivalente.

\section{Literatura Citada}

AGRICULTURAL AND FOOD RESEARCH COUNCIL - AFRC. Energy and protein requirements of ruminants. Wallingford: CAB International, 1993. p.159.

ALMEIDA, M.I.V.; FONTES, C.A.A.; ALMEIDA, F.Q. et al. Avaliação do crescimento de tecidos e órgãos de novilhos mestiços holandês-gir durante o ganho compensatório. 1. Carcaça. Revista Brasileira de Zootecnia, v.30, n.2, p.526534, 2001.

BAUMAN, D.E.; MCCUTCHEON, S.N.; STEINHOUR, W.D. et al. Sources of variation and prospects for improvement of productive efficiency in the dairy cow. Journal of Animal Science, v.60, p.583-592, 1985.
BORTONE, E.J.; MORRIL, J.L.; STEVENSON, J.S. et al. Growth of heifers fed 100 or $115 \%$ of National Research Council requirements to 1 year of age and then changed to another treatment. Journal of Dairy Science, v.77, p.270-277, 1994.

CHEN, G.; RUSSELL, J.B. Effect of monensin and a protonophore on protein degradation, peptide accumulation, and deamination by mixed ruminal microorganisms in vitro. Journal of Animal Science, v.69, n.5, p.2196-2203, 1991.

CHIZZOTTI, M.L. Avaliação da casca de algodão para novilhos de origem leiteira e determinação da excreção de creatinina e produção de proteína microbiana em novilhas e vacas leiteiras. Viçosa, MG: Universidade Federal de Viçosa, 2004. 132p. Dissertação (Mestrado em Zootecnia) Universidade Federal de Viçosa, 2004.

CHOI, Y.J.; HAN, K.I.; WOO, H.J. et al. Compensatory growth in dairy heifers: The effect of a compensatory growth pattern on growth rate in lactation performance. Journal of Dairy Science, v.80, p.519-524, 1997.

COCHRAN, R.C.; ADAMS, D.C.; WALLACE, J.D. et al. Predicting digestibility of different diets with internal markers: evaluation of four potential markers. Journal of Animal Science, v.63, p.1476-1483, 1986.

ERFLE, J.D.; BOILA, R.J.; TEATHER, R.M. et al. Effect of pH on fermentation characteristics and protein degradation by rumen microorganisms in vitro. Journal of Dairy Science, n.65, p.1457-1464, 1982.

FORD, A.J.; PARK, C.S. Nutritionally directed compensatory growth enhances heifer development and lactation potential. Journal of Dairy Science, v.84, p.1669-1678, 2001.

FREITAS, A.R.; PRESOTTI C.V.; TORAL, F.L.B. Alternativas de análises em dados de medidas repetidas de bovinos de corte. Revista Brasileira de Zootecnia, v.28, n.6, p.2233-2244, 2005 (supl).

GOODRICH, R.D.; GARRET, J.E.; GAST, D.R. et al. Influence of monensin on the performance of cattle. Journal of Animal Science, v.58, p.1484-1498, 1984.

LADEIRA, M.M.; VALADARES FILHO, S.C.; LEÃO, M.I. et al. Eficiência microbiana, concentração de amônia e pH ruminal e perdas nitrogenadas endógenas, em novilhos Nelore. Revista Brasileira de Zootecnia, v.28, n.2, p.404-411, 1999.

LANA, R.P.; FONTES, C.A.A.; PERON, A.J. et al. Composição corporal e do ganho de peso e exigências de energia, proteína e 
macroelementos minerais ( $\mathrm{Ca}, \mathrm{P}, \mathrm{Mg}, \mathrm{Na}$ e $\mathrm{K}$ ) de novilhos de cinco grupos raciais. I. Conteúdo corporal e do ganho de peso em gordura, proteína e energia. Revista da Sociedade Brasileira de Zootecnia, v.21, n.3, p.528-537, 1992.

LANA, R.P.; RUSSELL, J.B.; van AMBURGH, M.E. The role of $\mathrm{pH}$ in regulating ruminal methane and ammonia production. Journal of Animal Science, v.76, p.2190-2196, 1998.

LICITRA, G.; HERNÁNDEZ, T.M.; van SOEST, P.J. Standardization of procedures for nitrogen fractionation of ruminant feeds. Animal Feed Science and Technology, v.57, p.347-358, 1996.

LORENZO-BERMEJO, J.; ROEHE, R.; RAVE, G. et al. Comparison of linear and nonlinear functions and covariance structures to estimate feed intake pattern in growing pigs. Livestock Production Science, v. 82, n.1, p.15-26, 2003.

LUCHIARI FILHO, A.; BOIN, C.; ALLEONI, G.F. et al. Efeito do ionóforo ICM39603 no desempenho e conversão alimentar de novilhos zebu alimentados com gramíneas tropicais. Boletim da Indústria Animal, v.47, n.2, p.169-172, 1990.

MILLER, T.L.; WOLIN, M.J. Inhibition of growth of methaneproducing bacteria of the ruminant forestomach by hydroxymethylglutaryl-ScoA reductase inhibitors. Journal of Dairy Science, v. 84, p.1445-1448, 2001.

NATIONAL RESEARCH COUNCIL - NRC. Nutrient requirements of dairy cattle. 7.rev.ed.Washington, D.C.: National Academy Press, 2001. 408p.

OBERBAUER, A.M.; CURRIE, W.B.; KROOK, L. et al. Endocrine and histologic correlates of dynamics of the metacarpal growth plate in growing rams. Journal of Animal Science, v.67, p.3124-3135, 1989.

OLIVEIRA, J.S.; QUEIROZ, A.C.; LANA, R.P. et al. Efeito da monensina e da própolis sobre a atividade de fermentação de aminoácidos in vitro pelos microrganismos ruminais. Revista Brasileira de Zootecnia, v.35, n.1, p.275-281, 2006

PARK, C.S., CHOI, Y.J., ERICKSON, G.M. et al. Effect of compensatory growth on regulation of growth and lactation: response of dairy heifers to a stair-step growth pattern. Journal of Animal Science, v.64, p.1751-1758, 1987.

PARK, S.C.; CHOI, Y.J.; KELLER, W.L. et al. Effects of compensatory growth on milk protein gene expression and mammary differentiation. FASEB Journal, v.2, p.2619-2624, 1988.

PEREIRA, J.R.A.; ROSSI JR., P. Manual prático de avaliação de alimentos. Piracicaba: Fundação de Estudos Agrários Luiz de Queiroz, 1995. 25p.

PIRLO, G.; CAPELLETI, M.; MARCHETTO, G. Effects of energy and protein allowances in the diets of prepubertal heifers on growth and milk production. Journal of Dairy Science, v.80, p.730-739, 1997.

RUMSEY, T.S. Monensin in cattle: introduction. Journal of Animal Science, v.58, n.6, p.1461-1464, 1984.
RUSSELL, J.B.; STROBEL, H.J. Minireview. Effect of ionophores on ruminal fermentation. Applied and Environmental Microbiology, v.55, p.1-6, 1989.

RUSSELL, J.B.; STROBEL, H.J.; CHEN, G. The enrichment and isolation of a ruminal bacterium with a very high specific activity of ammonia production. Applied and Environmental Microbiology, v.54, p.872-877, 1988.

SALLES, M.S.V., ZANETTI, M.A., CONTI, R.M.C. et al. Efeitos da monensina no desempenho de bezerras leiteiras em crescimento. Revista Brasileira de Zootecnia, v.30, n.4, p.1293-1298, 2001.

SILVA, D.J., QUEIROZ, A.C. Análise de alimentos (métodos químicos e biológicos). 3.ed. Viçosa: Editora UFV, 2002. 235p.

SILVA, R.M.N.; VALADARES, R.F.D.; VALADARES FILHO, S.C. et al. Uréia para vacas em lactação. 2. Estimativas do volume urinário, da produção microbiana e da excreção de uréia. Revista Brasileira de Zootecnia, v.30, n.6, p.1948-1957, 2001.

STATISTICAL ANALYSIS SYSTEMS - SAS. User's guide. Version 8.1. Cary: North Carolina State University, 2000. 1686p.

TYRRELL, H.F.; MOE, P.W. Effect of intake on digestive efficiency. Journal of Dairy Science, v.58, p.1151-1163, 1975.

VALADARES, R.F.D; GOLÇALVES, L.C.; RODRIGUEZ, N.M. Níveis de proteína em dietas de bovinos. 2. Consumo, digestibilidades e balanço de compostos nitrogenados. Revista Brasileira de Zootecnia, v.30, n.6, p.1259-1263, 1997.

Van AMBURGH, M.E.; GALTON, D.M.; BAUMAN, D.E. et al. Effects of three prepubertal body growth rates on performance of Holstein heifers during first lactation. Journal of Dairy Science, v.81, p.527-538, 1998

Van SOEST, P.J. Nutritional ecology of the ruminant. Ithaca: Cornell University Press, 1994. 476p.

Van SOEST, P.J.; ROBERTSON, J.B.; LEWIS, B.A. Methods of dietary fiber, neutral detergent fiber, and nonstarch polysaccharides in relation to animal nutrition. Journal of Animal Science, v.74, p.3583-3597, 1991.

VANDEHAAR, M.J. Efficiency of nutrient use and relationship to profitability on dairy farms. Journal of Dairy Science, v.81, p.272-282, 1998.

WALFORD, R.L.; CREW, M. How dietary restriction retards aging: An integrative hypothesis. Growth Development Aging, v.53, p.139-140, 1989.

WIDDOWSON, E.M.; LISTER, D. Nutritional control of growth. In: PEARSON, A.M.; DUSTON, T.R. (Eds.) Growth regulation in farm animals: advances in meat research. New York: Elservier, 1991. v.7. p.67-101. 